\title{
Investigation of the parameters influencing pulsed laser assisted turning of DIN. 1.2379 tool steel
}

\author{
Original \\ Article \\ Amro M. Youssef ${ }^{1}$, Ahmed M. Kohail' ${ }^{2}$, Mohamed Hussien Bakir ${ }^{3}$ \\ ${ }^{1}$ Military Technical College, ${ }^{2}$ Department of Engineering, Modern Academy for Science \\ and Engineering, ${ }^{3}$ Egyptian Ministry of Defense, Cairo, Egypt
}

\section{Keywords:}

Laser assisted turning, (LAT), laser assisted machining (LAM), Nd-YAG laser.

\section{Corresponding Author:}

Amro M. Youssef, Military Technical College, Cairo, Egypt, Tel: 24036110, Email: amro.youssef@mtc.edu.eg

\section{Abstract}

Hard steels are extensively used in gamut of uses such as aerospace, vehicles and die and mold industries. These materials have high strength and hard- ness which leads to a difficulty in their manufacturing. In addition to the required high forces during the production by machining and the resulting tool wear, it needs machine tools with high stiffness. Such characteristics will result in a production cost that can reach half of the product cost and high investments in addition to the need for subsequent finishing operations. Laser assisted machining (LAM) represents a new step towards a promising technique for machining new materials that are difficult to machine. It offers local heating of the work before conventional cutting takes place. Tool steel is an important example of these materials. In this work laser assisted turning of tool steel DIN 1.2379 is investigated. Nd:YAG pulsed laser head of 350 $\mathrm{W}$ power is used to assist conventional turning operation. For process evaluation, a comparison of conventional and LAM was introduced considering tool life, cutting forces. The influences of different cutting speeds, depth of cuts and laser powers were discussed. The experimental results showed a considerable increase of tool life, a reduction in cutting forces, when using LAM in turning operation.

\section{INTRODUCTION}

The concept of assisting the material shearing mechanism during ma- chining process by pre-heating methods has been used for several decades. Imprecise heat sources such as Flame torches, Electric ResistanceInduction in addition to Plasma had been previously used $^{[1]}$.

Recently, lasers have emerged as a feasible heating means, favored for generating focused energy in a required cutting area. In (LAM) process of metals a High Power Laser (HPL) is utilized to provide local heating of the work-piece prior to the shearing by the conventional tool. Rajagopal et al. (1982) $)^{[2]}$, Anderson et al. (2006) ${ }^{[3]}$ has experimented using a Fourteen $\mathrm{kW}$ Carbon-Di-Oxide laser source on Titanium and Inconel718. The results showed that beam position is critical during LAM. LAM is used to accurately control the energy and heated spot, thus avoiding any un-desirable effect on the workpiece surface. Therefore, it has a much desired effect on subsurface layer properties of workpiece. Abdulghani et al. $(2013)^{[4]}$ constructed a model for the prediction of the absorbed energy and depth of the heat affected layer to preserve the workpiece mechanical properties.

Advantages of the process also include an increase in metal rate of re- moval and less probability of, self induced "Chatter" vibration, initiation and catastrophic cutting tool failures. Different researchers have also re- ported a decrease in the cutting force components, increase of tool life, and improvement in the capability of cutting brittle materials without any ob- servable cracks ${ }^{[5]}$. LAM was reported in cutting different materials such as; ceramics, Nickel-Based alloys and materials with tendency to show strain hardening such as Grades 304 or 316L Stainless Steels. In the research car- ried out by Jahanmir et al. $(1999)^{[6]}$, they found a considerable increase in tool life during LAM of hot pressed silicon nitride and ceramics.

Another work by Lei et al. $(2000)^{[7]}$, investigated the metallurgical properties of workpiece material around the shear zone. Increased mobility of the grains, which resemble rod-shape silicon nitride, by the decrease in viscosity of the irregular glassy phase at higher workpiece temperatures which leads to an improvement in cutting process conditions. . Rebro et al. (2002) ${ }^{[8]}$ and Pfefferkorn et al. (2004) ${ }^{[9]}$, found a significant contrast between tool wear pattern in the unassisted and LAM of mullite ceramics having uncoated K313 inserts. They also attributed the mode of tool wear to be adhesion and they proposed that there is an optimum temperature range where flank wear is minimum. Wang et al. (2002) $)^{[10]}$, 
studied LAM of an alumina reinforced aluminum metal matrix composite and reported that it has reduced cutting forces by $30-50 \%$ and reduced tool wear of the carbide by $20-30 \%$ during the machining. In the work by Khan $(2004)^{[11]}$, and Dumitrescu et al. (2006) $)^{[12]}$, diode generated laser was used in cutting AISI-D2 steel. Reduc- tion in tool wear and increase in turning tool life were observed. The same material was investigated using crystal laser by Baker et al. (2006) ${ }^{[13]}$. Other ferrous alloys were investigated like compacted graphite cast iron but using pulsed Crystal laser ${ }^{[14]}$, AISI4130 ${ }^{[15]}$ and white chromium cast iron $^{[16]}$ to investigate the surface roughness and cutting forces. It was noticed that the absorbing ability of the work material leads to greater reduction in forces at lower power range. These observations are also true even when ma- chining low machinability materials as Inconel $718^{[17,18]}$ and Titanium ${ }^{[19,20]}$. The work by Ding and Shin $(2010)^{[15]}$ used three dimensional simulation for the investigation of surface quality resulting from the process. Die steel DIN 1.2379 is the focus of this work. It has excellent wear resis- tance and deep hardening characteristics therefore; it is widely used in the manufacture of blanking and cold forming dies. Laser-assisted machiningturning (LAM-T) of this Die steel is investigated using pulsed laser source. The influence of different operating parameters when using LAM is investigated by measuring cutting forces and tool wear. Statistical plots are developed as a selection guide for the suitable process parameters.

\section{EXPERIMENTAL WORK}

The experimental arrangement was prepared using Nd:YAG pulsed laser head type JK702H by GSI LUMINICS with maximum power of $350 \mathrm{~W}$ and a lathe with $1.3 \mathrm{KW}$ motor power and discrete spindle speed gear box. In this specific turning process, the direction of Laser beam was inclined to the axis of the workpiece (Figure 1) to prevent the interruption of beam by the chips formed at the cutting point. Coated carbide tools of grade GC3015 (by SANDVIK ) with nose radius $0.4 \mathrm{~mm}$ and setting angle of $45^{\circ}$ were used. During each experiment a fresh cutting edge was used. Cutting forces were recorded during each cutting pro- cess using a three component dynamometer KISTLER type:9263 and multi channel charge amplifier type: 5070A. Tool life was measured using optical microscope type OLYMPUS BX41M with magnification up to $1500 \mathrm{X}$.

DIN 1.2379 steel specimens with length $120 \mathrm{~mm}$ and $20 \mathrm{~mm}$ diameter were prepared. The alloy composition is shown in table $1^{[21]}$. The measured average hardness for the prepared test specimens was 56 HRC. The hardness was tested on different places on the work-piece surface to ensure the quality of the material included in this research work.
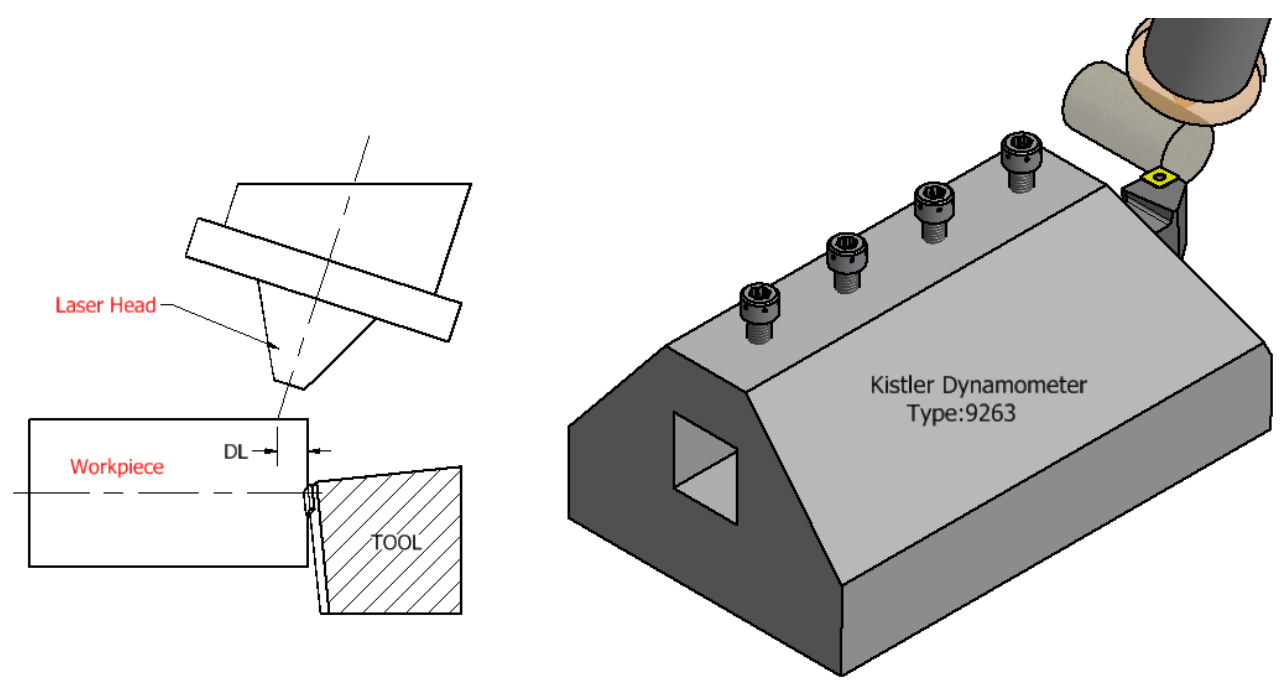

Fig. 1: Laser beam Alignment w.r.t workpiece

Table 1: Chemical Composition of DIN 1.2379 tool steel

\begin{tabular}{llllllll}
\hline Elemen & \multirow{2}{*}{ Carbon } & Chrome & Molybdenum & Vanadium & Manganese & Silicon & Nickel \\
\hline Weight (\%) & 1.55 & 11.8 & 0.8 & 0.8 & 0.4 & 0.3 & 0.3 \\
\hline
\end{tabular}


A preheat time of $5 \mathrm{sec}$ was required, in order for the steady-state tem- perature to be achieved on the surface of workpiece. The determination of the suitable Laser beam advance distance is chosen based on the measured minimum cutting force as shown in Figure 2.

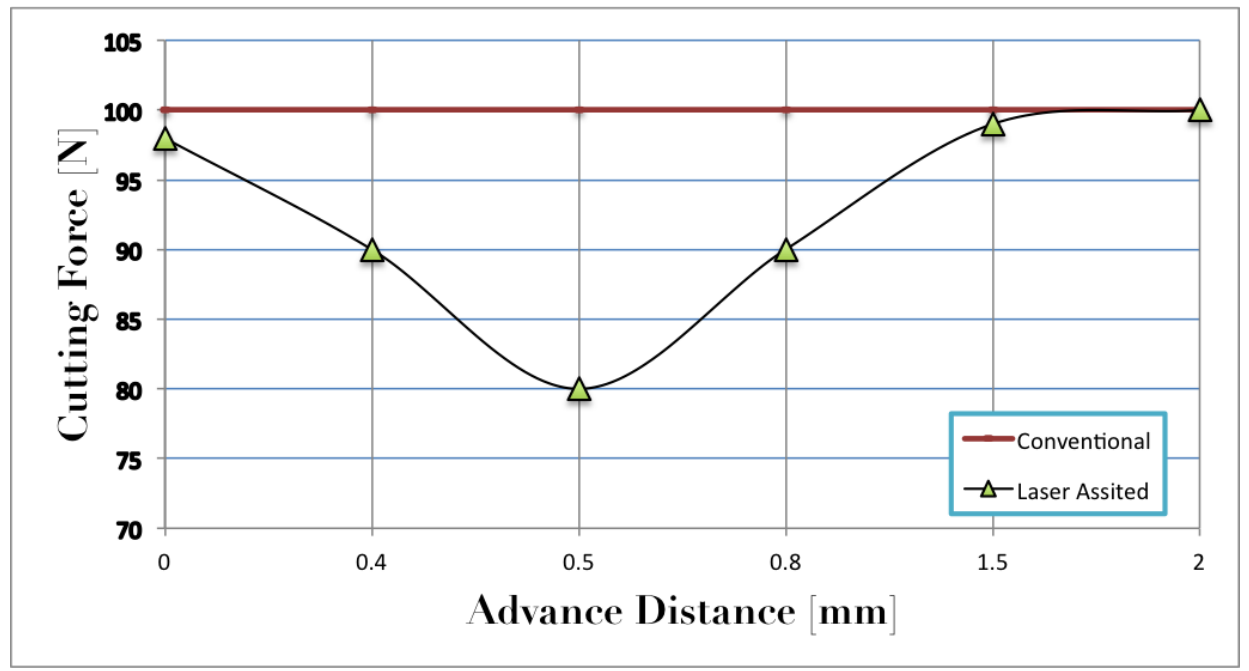

Fig. 2: Selection of optimum beam advance position at $\mathrm{n}=900 \mathrm{rpm}$

\section{RESULTS AND DISCUSSIONS}

\subsection{Effect of LAM Process Parameters on Tool Life}

The tool life measuring criteria may be evaluated using either the cut- ting time or work piece cut length until reaching a standard tool wear value. Comparisons of tool wear behavior at 900 r.p.m with different laser power are shown in Figures 3, 4. Initial tool wear is slightly the same at the beginning, but it progresses slowly during laser assisted turning, leading to the increase of tool life specially for higher laser power. This might be at- tributed to the softening of the work-piece in the primary shear zone. When machining using conventional turning process, the tool life for a flank wear is evaluated according to a criterion value of $600 \mu \mathrm{m}$, according to ISO 3685- 1993 standard, corresponded to a cut length of 822 $\mathrm{mm}$. For the tests of $100 \mathrm{~W}$ Laser power, the Laser spot diameter was $1 \mathrm{~mm}$., which resulted in a power density of $12.7 \mathrm{KW} / \mathrm{cm} 2$. It was found that laser power intensity was not high enough to affect the strength in the immediate area around the shear zone by the softening caused by the heating effect. The flank side of the insert was abraded by hard carbide chromium particles from the die steel.The flank wear progresses more slowly with increasing laser power (Figure 3) and tool life was extended 1.8 times.

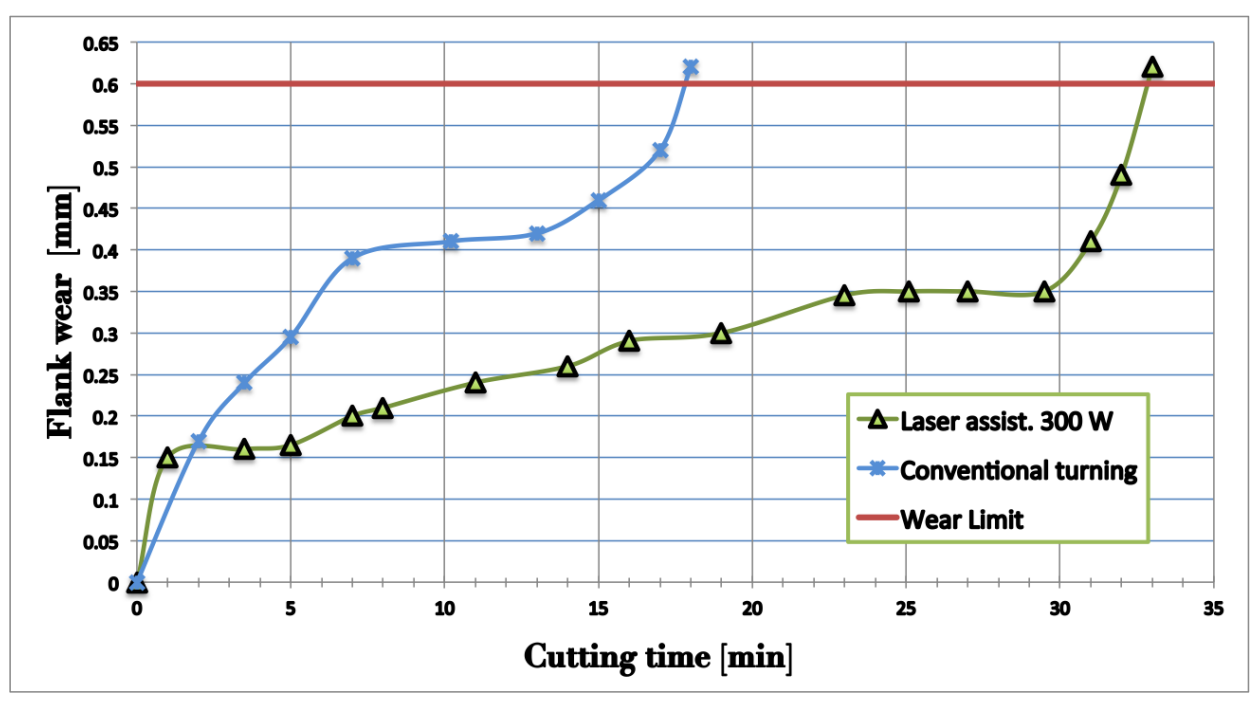

Fig. 3: The effect of LAM on cutting edge life 


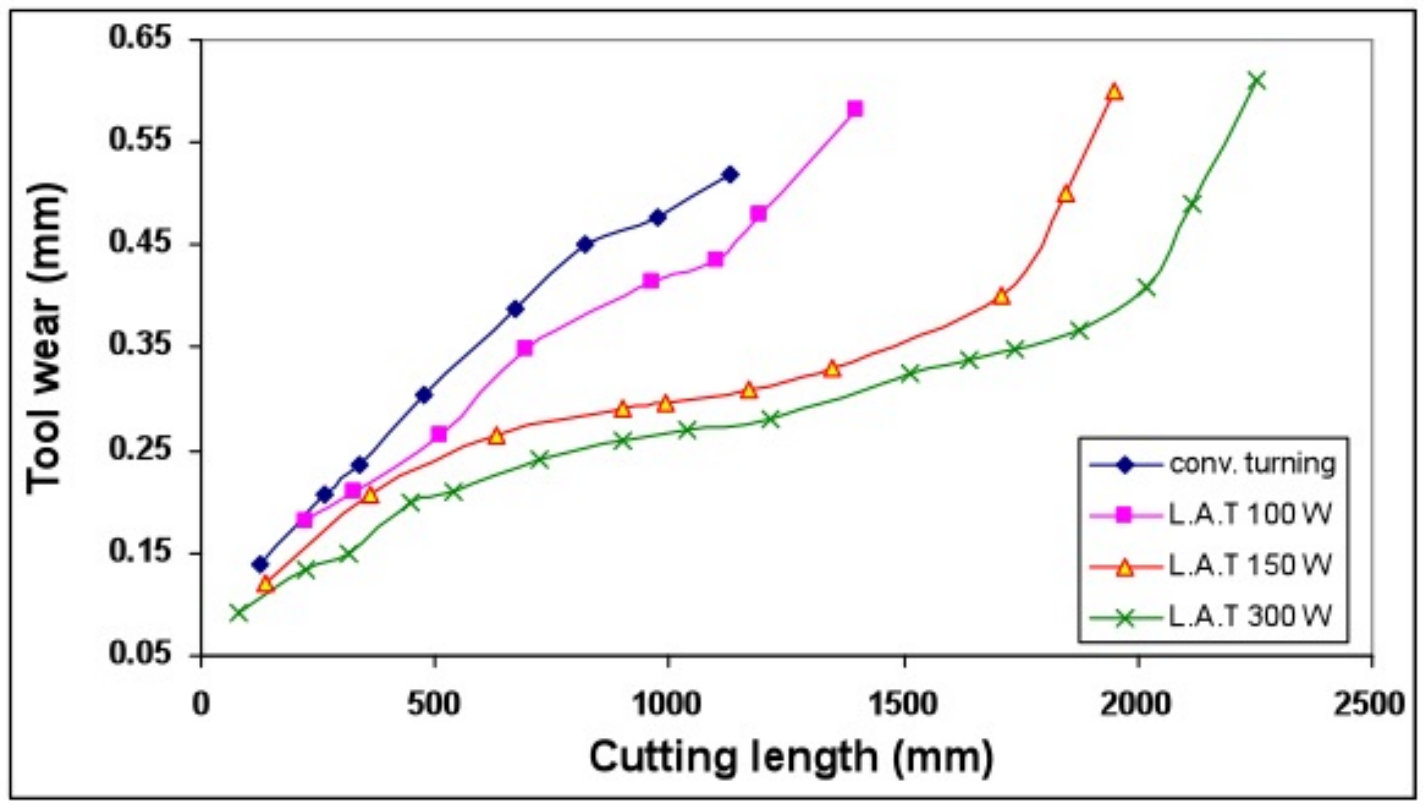

Fig. 4: The effect of Cutting length and laser power on tool wear

Different combinations of speed and laser power were used to find the best conditions. Figure 5 shows the tool life obtained at different laser power and spindle speeds. It was found that at 900 r.p.m with a laser power of $300 \mathrm{~W}$ an increase in tool life by 1.4 times was obtained. While at 1400 r.p.m.a 0.75 times increase in tool life was obtained. The increase of cutting speed must be accompanied by an increase in the Laser beam density to obtain a better tool life. At different depth of cut using different laser power, it was found that power density was not high enough with increasing depth of cut to reduce the strength in the immediate area around of the shear zone by softening caused by heating effect on the work-piece. Lack of thermal softening of workpiece when increasing depth of cut, results in a demising effect of LAM on tool life as shown in Figure 6. These experimental results were verified using thermal model and reported in (4) and found to be in good correlation as shown in Figure (7)

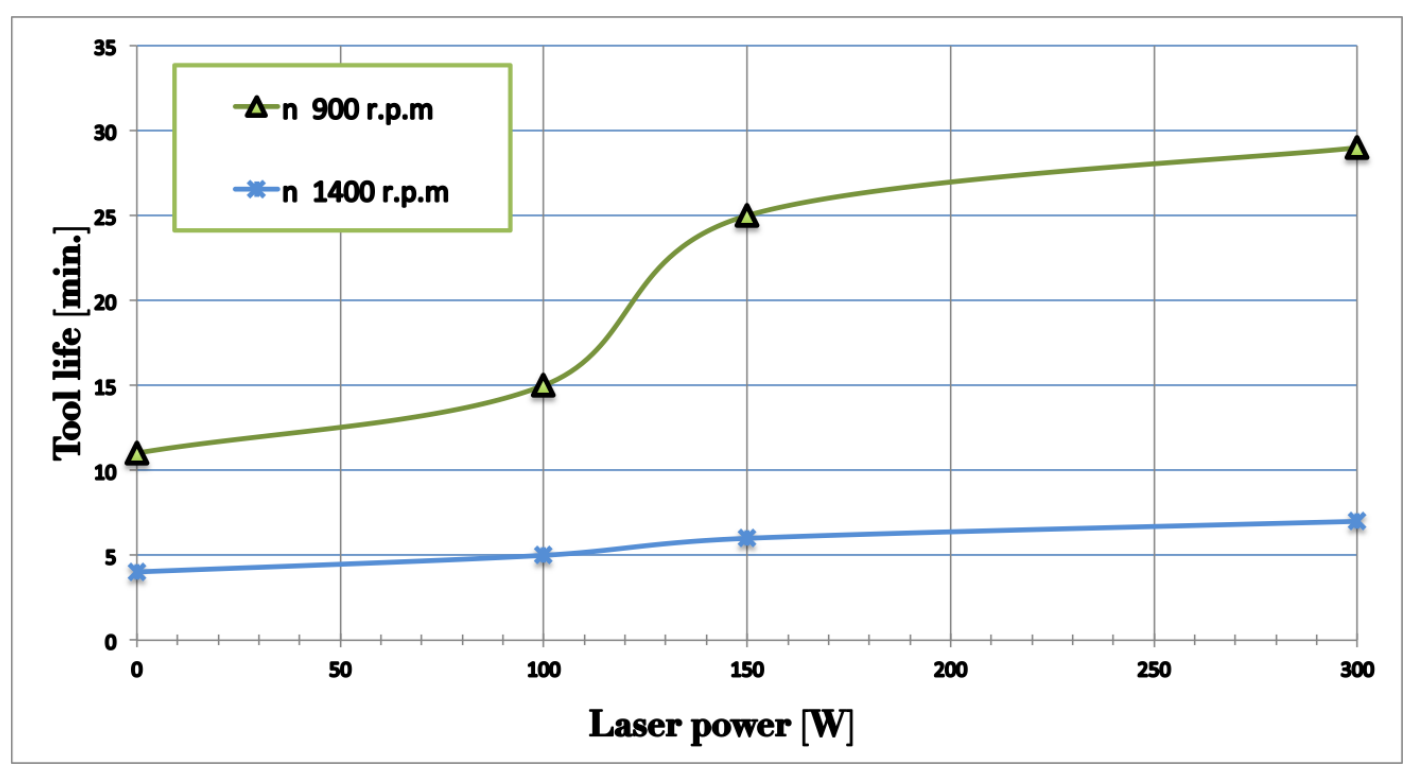

Fig. 5: The effect of cutting speed and laser power on tool life 


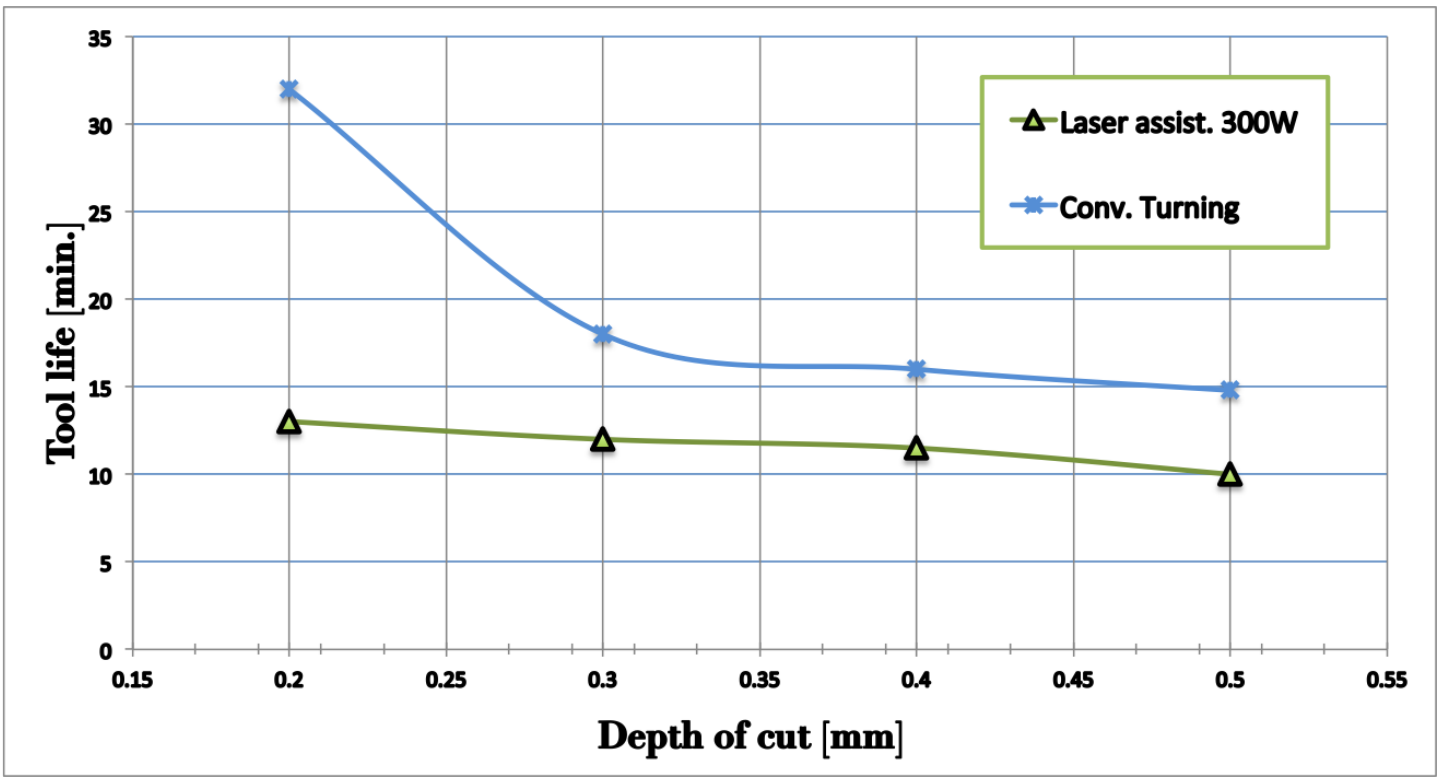

Fig. 6: The effect of cutting depth on tool life

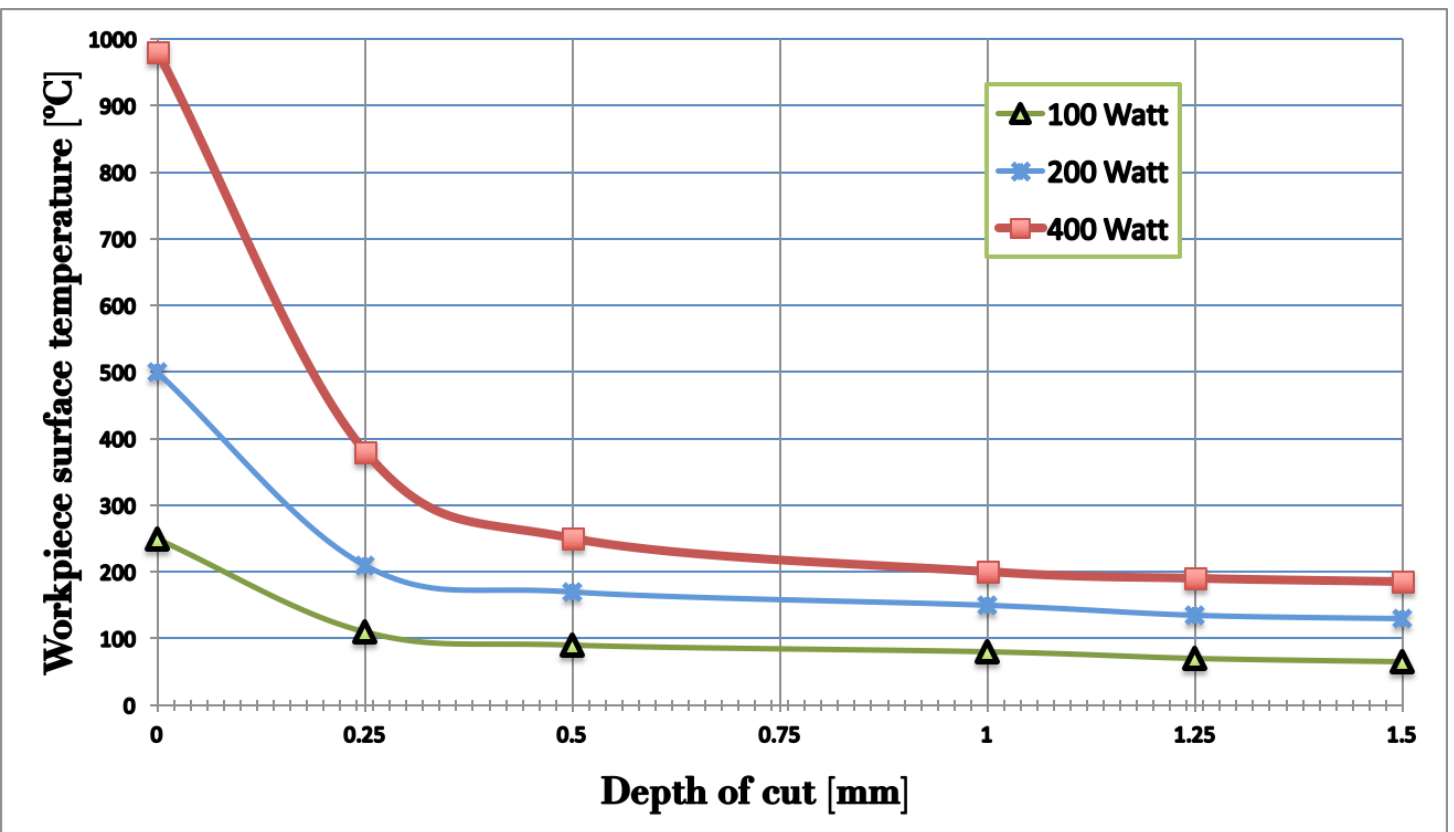

Fig. 7: Thermal modeling of LAM 


\subsection{EffectS of LAM Process Parameters on the} Cutting Resistance

In LAM, the resisting forces for machining are influenced not only by process parameters such as; feed rate, cutting speed and depth of cut, but also by the additional heat generated by the laser beam. Figure 8 presents the decrease in cutting force components by increasing laser power. This is explained by the increase of workpiece temperature as affected by increasing Laser energy in the cutting spot, which makes the workpiece material more ductile and easy to flow on the face of the turning insert. The thermal softening at elevated temperatures changes the failure mode from being pre- dominantly fractured to plastic deformation. The percentage reduction in cutting force components was around $26-35 \%$ in radial direction, $18-25 \%$ in tangential direction and around $13-33 \%$ in axial direction as shown in Figure 9. The percentage reduction in resultant cutting force in "LAT" ranged from $20 \%$ to $33 \%$ for laser powers from 100 to $300 \mathrm{~W}$ at $0.08 \mathrm{~mm}$./rev. feed and cutting depth of $0.4 \mathrm{~mm}$. All the experiments to study the influence the cutting depth were performed at constant spindle speeds with different laser power to determine the depth to which the laser heats the subsurface layer. The influence of different cutting depths on resultant force at variable laser power with fixed speed of lathe spindle of 900 r.p.m. and feed 0.08 mm./rev. is shown in Figure 10.

\subsection{Statistical Treatment of Experimental Results}

Minitab, statistical analysis software was used to construct contour plots for determination of both tool life and percentage reduction in cutting forces (Figure 11, 12). The contour plots construction was based on the de- termination of the regression equations using the experimental results. The obtained contour plots are useful for determination of suitable operating conditions for the required values of both tool life and percentage reduction in cutting force with a correlation factor more than 0.95 .

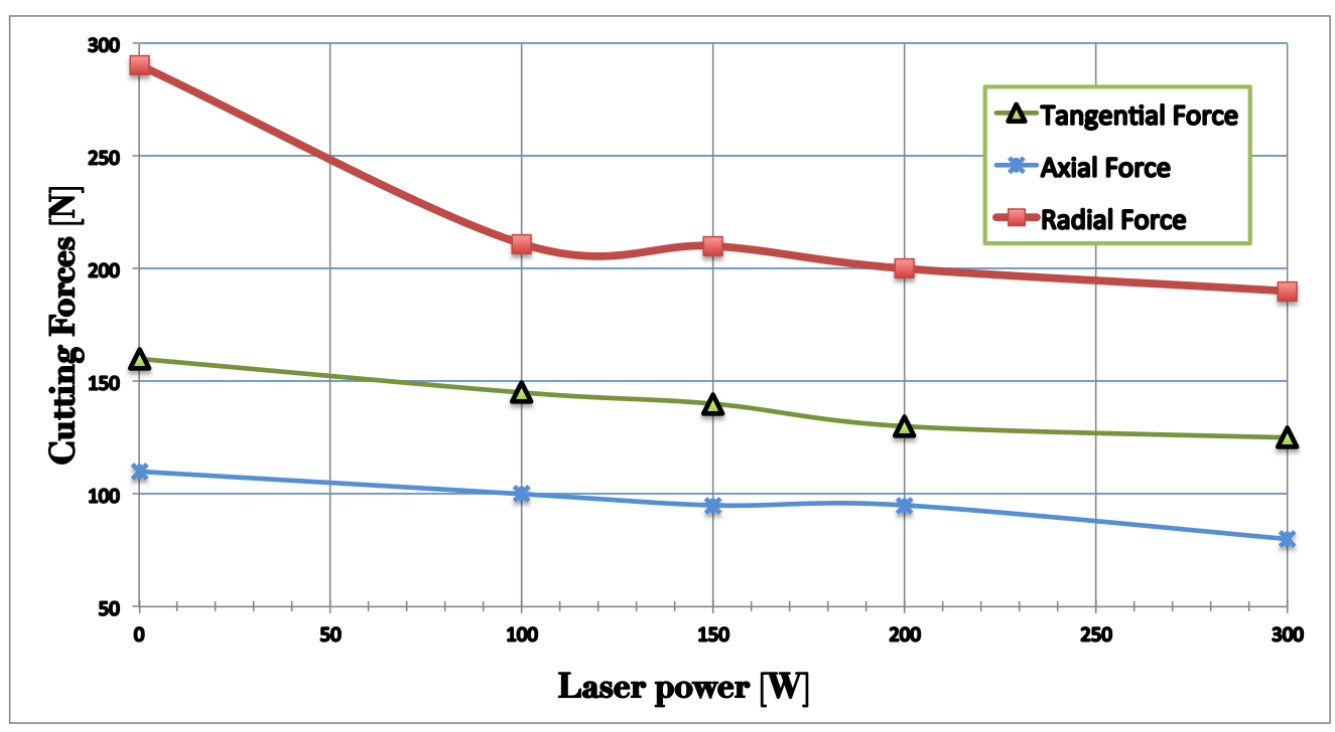

Fig. 8: The effect of Laser power on cutting force components

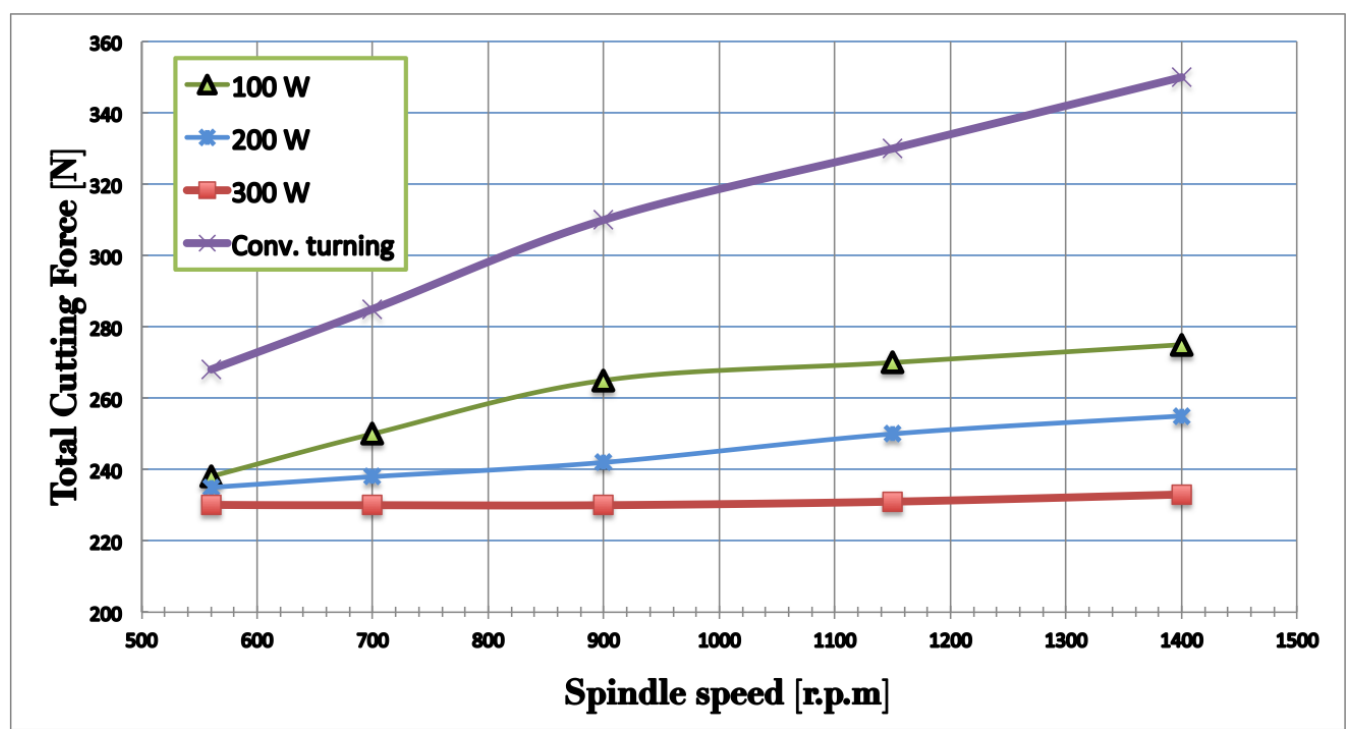

Fig. 9: The effect of spindle speed and Laser power on resultant cutting force 


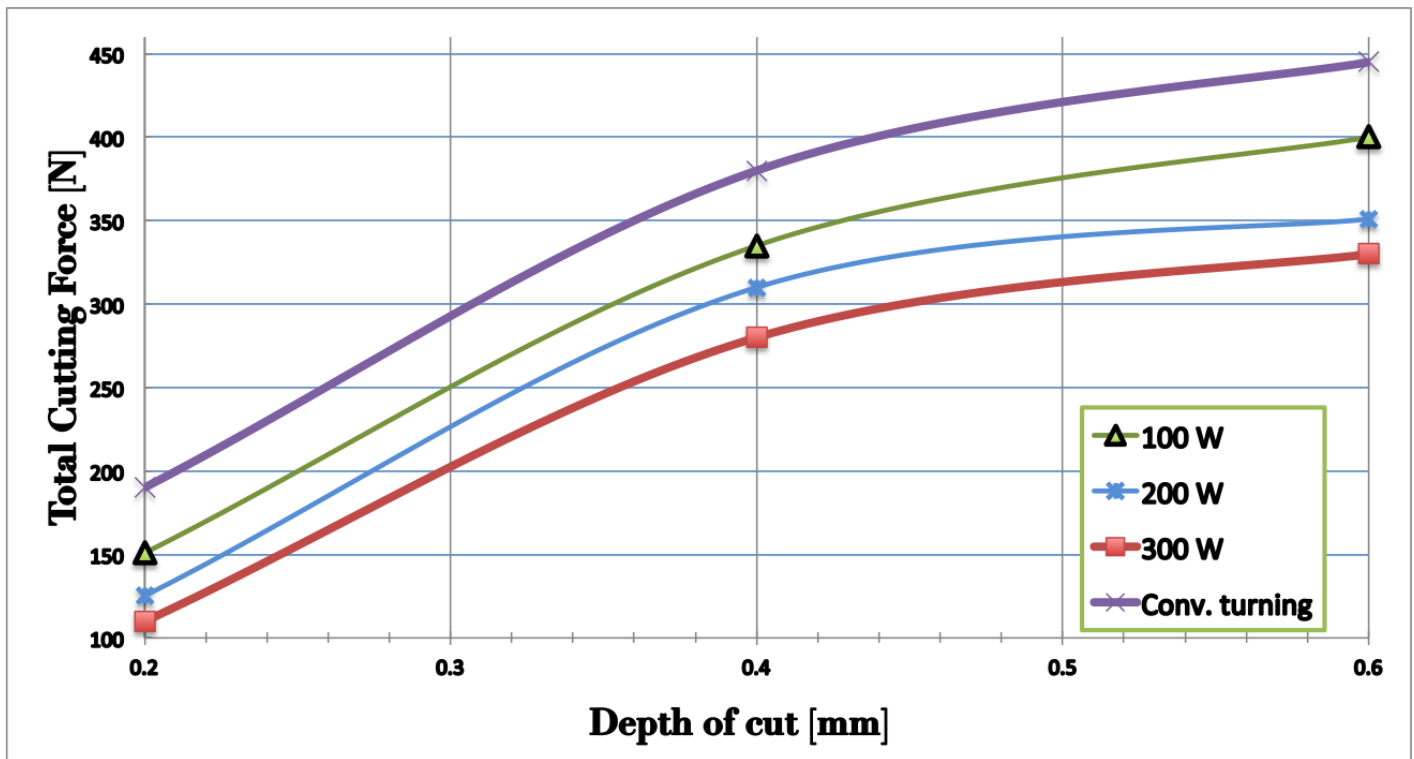

Fig. 10: The Effect of cutting depth on resultant cutting force at various Laser power ( $\mathrm{n}=900$ r.p.m., feed rate 0.08 mm./rev.)

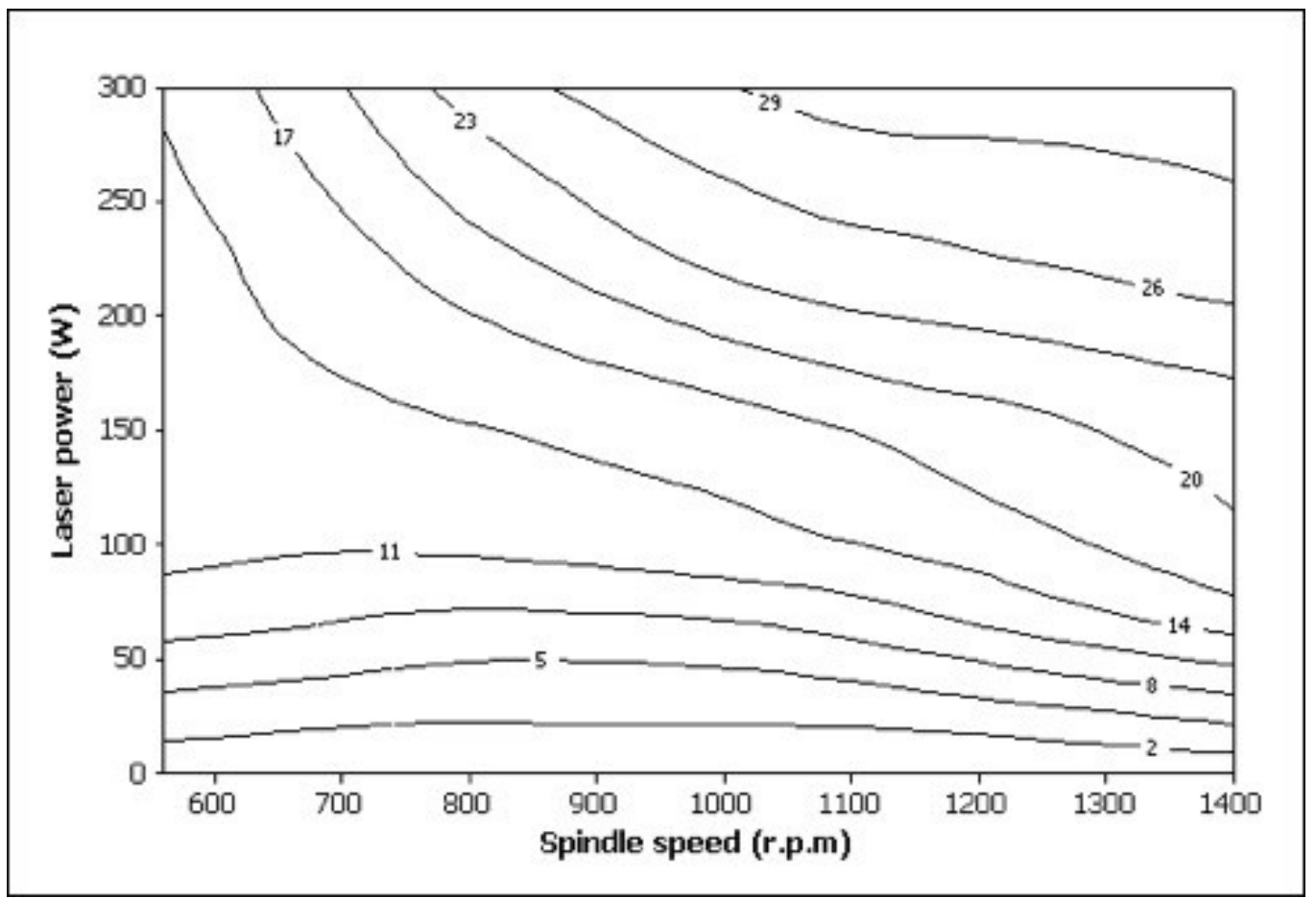

Fig. 11: Contour plot for determination of percentage reduction in resultant cutting force by selecting both spindle speed and Laser power (depth of cut $0.2 \mathrm{~mm}$.) 


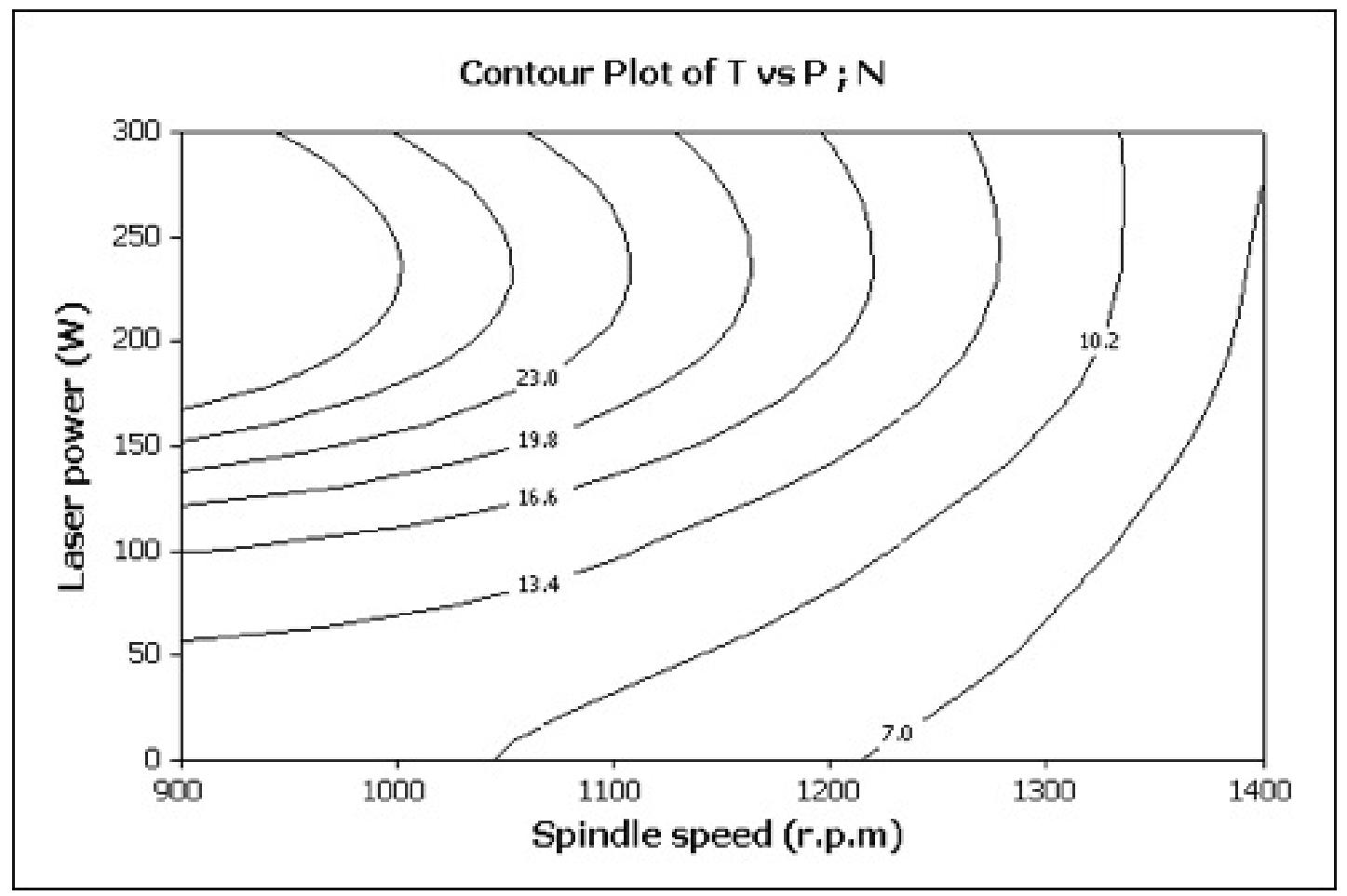

Fig. 12: Contour plot for determination of tool life by selecting both spindle speed and Laser power (at depth of cut $0.2 \mathrm{~mm}$ )

\section{CONCLUSIONS}

In this work, laser assisted turning process of hardened DIN 1.2379 tool steel using Nd:YAG pulsed laser has been investigated. From the obtained results it can be concluded that:

- The increase of tool life using LAM can reach 1.8 times and more using higher cutting speeds accompanied by higher values of laser power.

- The increase of depth of cut can represent an obstacle for material softening and consequently the increase of tool life is limited at higher depths.

- A considerable decrease in cutting forces was noticed when using LAM compared with conventional turning process which is mainly due to material softening process. The percentage reduction in cutting forces is much influenced by cutting speeds, cutting depth and Laser power.

- A thermal model was developed to verify the findings of the research and aids in generalizing the results. this will help in easily applying the results in other difficult to cut materials

- Contour plots which are obtained from the statistical treatment of experimental results are useful for determination of suitable operating conditions when using LAM with an accepted correlation factor.

\section{REFERENCES}

[1] Y. C. Shin C. E. Leshock, J. N. Kim. Plasma enhanced machining of inconel 718: modeling of workpiece temperature with plasma heating and experimental result. International Journal of Machine Tools and Manufacture, 41(6):877-897, 2001

[2] S. Rajagopal, D. Plankenhorn, and V. Hill. Machining aerospace alloys with the aid of a $15 \mathrm{kw}$ laser. Journal of Applied Metalworking, $2: 170-184,1982$

[3] Mark Anderson, Rahul Patwa, and Yung C. Shin. Laser-assisted machining of inconel 718 with an economic analysis. International Journal of Machine Tools and Manufacture, 46(14):1879 - 1891, 2006.

[4] Omar M. Abdulghani, Mohamed Sobih, Amro M. Youssef, and Abdel- Monem El-Batahgy. Modeling and simulation of laser assisted turning of hard steels. Modeling and Numerical Simulation of Material Science, 3:106-113, 2013.

[5] S. Karagiannis G. Chryssolouris, N. Anifantis. Laser assisted machining: An overview. Transaction of American Society of Mechanica Engineering- Journal Of Mechanical Design, 119(4b):766-769, 1997.

[6] Said Jahanmir, M Ramulu, and Philip Koshy. Machining of ceramics and composites, volume 53. Marcel Dekker, New York, 1999.

[7] Shuting Lei, Yung C Shin, and Frank P Incropera. Deformation mechanisms and constitutive modeling for silicon nitride undergoing laserassisted machining. International Journal of Machine Tools and Manufacture, 40(15):2213 - 2233, 2000.

[8] Patrick A. Rebro, Yung C. Shin, and Frank P. Incropera. Laserassisted machining of reaction

sintered mullite ceramics. Journal of Manufacturing Science and Engineering, 124(4):875-885, 2002.

[9] Frank E. Pfefferkorn, Yung C. Shin, Yinggang Tian, and Frank P. Incr- opera. Laser-assisted machining ofmagnesia-partially-stabilized zirco- nia. Journal of Manufacturing Science and Engineering, 126(1):42-51, 2004

[10] Y Wang, L.J Yang, and N.J Wang. An investigation of laser-assisted ma- chining of al2o3 particle reinforced aluminum matrix composite. Journal of Materials Processing Technology, 129(1):268 - 272, 2002.

[11] Adnan Rashid Khan. Laser assisted machining. Master's thesis, McMaster University, 2004.

[12] P. Dumitrescu, P. Koshy, J. Stenekes, and M.A. Elbestawi. Highpower diode laser assisted hard turning of aisi d2 tool steel. Internationa Journal of Machine Tools and Manufacture, 46(15):2009 - 2016, 2006. 
[13] Mohamed H. Baker, Amro M. Youssef, Ahmed M. Kohail, and Wael S. Moughith. The infuence of laser assisted turning parameters on cutting forces new approach. In 12th AMME Conference, pages 10-25, Kobry El Koba, Cairo, Egypt, May 2006. Military Technical College.

[14] S. Skvarenina and Y.C. Shin. Laser-assisted machining of compacted graphite iron. International Journal of Machine Tools and Manufacture, 46(1):7 - 17, 2006.

[15] Hongtao Ding and Yung C. Shin. Laser-assisted machining of hardened steel parts with surface integrity analysis. International Journal of Machine Tools and Manufacture, 50(1):106 - 114, 2010.

[16] Syed Hasan Masood, Kelly Armitage, and Milan Brandt. An experimental study of laser-assisted machining of hard-to-wear white cast iron. International Journal of Machine Tools and Manufacture, 51:450-456, 2011
[17] H. Attia, S. Tavakoli, R. Vargas, and V. Thomson. Laser-assisted high- speed finish turning of superalloy inconel 718 under dry conditions. CIRP Annals - Manufacturing Technology, 59(1):83 - 88, 2010.

[18] Mohamed Balbaa and Mohamed Nasr. Prediction of residual stresses after laser-assisted machining of inconel 718 using sph. Procedia CIRP 31, 122015 .

[19] R. Bejjani, B. Shi, H. Attia, and M. Balazinski. Laser assisted turning of titanium metal matrix composite. CIRP Annals - Manufacturing Technology, 60(1):61 - 64, 2011

[20] Witold Habrat. Experimental investigation of effect of the laserassisted finish turning of ti-6al-4v alloy on machinability indicators. Solid State Phenomena, 261:135-142, 082017.

[21] Rafael A. Mesquita, editor. Tool Steels Tool steels, Properties and Per- formance. Number ISBN 9781439881712 in 1. CRC press, 2017. 